\title{
Improved Response Rates with Bortezomib in Relapsed or Refractory Multiple Myeloma: An Observational Study in Chinese Patients
}

\author{
MaoFang Lin · Jian Hou • WenMing Chen • XiaoJun Huang • ZhuoGang Liu • YuHong Zhou • \\ Yan Li $\cdot$ Taiyun Zhao $\cdot$ LinNa Wang $\cdot$ Kwang-Wei Wu $\cdot$ ZhiXiang Shen
}

To view enhanced content go to www.advancesintherapy.com

Received: July 24, 2014 / Published online: October 21, 2014

(c) The Author(s) 2014. This article is published with open access at Springerlink.com

\section{ABSTRACT}

Introduction: Bortezomib, a novel proteasome inhibitor, is approved for the treatment of relapsed multiple myeloma (MM). Efficacy and safety of bortezomib is well known; however, it was necessary to validate the data in patients with different ethnic backgrounds. The efficacy and safety of bortezomib was assessed in

Trial registration: Clinicaltrials.gov \#NCT01675245.

Part of these data was presented at American Society of Hematology (ASH) 49th Annual Meeting and

Exposition, December 8-11, 2007, Atlanta, Georgia; American Society of Hematology (ASH) 50th Annual Meeting and Exposition, December 6-9, 2008, San Francisco, California; and XII International Myeloma Workshop, February 26 to March 1, 2009, Washington, DC; and 14th International Myeloma Workshop (IMW), April 3-7, 2013, Kyoto, Japan.

Electronic supplementary material The online version of this article (doi:10.1007/s12325-014-0159-z) contains supplementary material, which is available to authorized users.

M. Lin

Department of Hematology, The First Affiliated Hospital, College of Medicine, Zhejiang University, Zhejiang, China

J. Hou

The Myeloma and Lymphoma Center, Changzheng Hospital, The Second Military Medical University, Shanghai, China patients from China with relapsed/refractory MM in a real-world scenario.

Methods: This prospective, non-interventional, observational study enrolled both male and female Chinese patients, aged $\geq 18$ years and diagnosed with relapsed or refractory MM. Administration of intravenous bortezomib at $1.3 \mathrm{mg} / \mathrm{m}^{2}$ was recommended twice a week for 2 weeks (days 1, 4, 8 and 11), followed by a 10-day rest period (maximum of 8 cycles) and a follow-up every 12 weeks for 3 years. Efficacy assessments included best response, objective response rate (ORR), time to response, duration of response, and overall survival. Safety was also assessed.

Results: A total of 517 patients were enrolled with a median age of 58.7 years. Patients predominantly had immunoglobulin $G$ type $(46.2 \%)$ and stage III (47.8\%) myeloma. Overall, 202 (42.3\%) patients had partial response as best response, ORR was $88.9 \%$ and

W. Chen

Beijing Chao-Yang Hospital, Capital Medical

University, Beijing, China

X. Huang

Peking University People's Hospital, Beijing, China 
the proportion of patients exhibiting complete response was $24.7 \%$. The median time to response observed was 27 (21-40) days. Median time to progression was 415 days and median overall survival was 475 days. Thrombocytopenia (14.4\%) was the most common adverse event.

Conclusion: Bortezomib demonstrated clinical response in majority of patients and was well tolerated in this observational study in Chinese patients with relapsed/refractory MM.

Keywords: Bortezomib; Chinese; Multiple myeloma; Observational study; Refractory; Relapsed; Response

\section{INTRODUCTION}

Multiple myeloma (MM) is a relatively rare hematological malignancy that affects $\sim 1-9$ in 100,000 individuals each year worldwide with a higher incidence in North America (7.1 in 100,000 per year) [1]. Although considerably prevalent in developed Western countries, prevalence statistics are substantially lower in

\section{Z. Liu}

Shengjing Hospital of China Medical University, Shenyang, Liaoning, China

Y. Zhou

Department of Hematology of Zhejiang Province Traditional Chinese Medical Hospital, Shenyang, Liaoning, China

Y. Li

The First Affiliated Hospital of China Medical University, Shenyang, Liaoning, China

T. Zhao $\cdot$ L. Wang $\cdot$ K.-W. Wu

Xian-Janssen Pharmaceutical Company, Beijing, China

\section{Z. Shen (ه)}

Ruijin Hospital, Shanghai Jiaotong University School of Medicine, 197 Ruijin 2nd Rd, Luwan District, Shanghai, China

e-mail: drshenzx@126.com developing countries, including Asian countries [2]. An epidemiological study in Taiwan reported an average incidence of 0.75 per $100,000 \mathrm{MM}$ patients with a mortality rate of 0.59 per 100,000 deaths [3].

This incurable disease, which has a median survival of 5 years, poses the major challenge of multiple relapse $[4,5]$. The standard of care for MM includes alkylating agents, anthracyclines and corticosteroids with or without hematopoietic stem cell rescue, or high-dose therapy with hematopoietic stem cell rescue [6]. Although this conventional approach offers adequate disease control, treatment benefit durability is limited and disease progression is almost inevitable. Over the last decade, the therapeutic approach for MM has evolved and the treatment paradigm has shifted to novel drugs that target different mechanistic pathways, such as immunomodulatory drugs (thalidomide and lenalidomide) and proteasome inhibitors (e.g., bortezomib) [1, 7-9]. These new agents have been extensively studied in the relapsed or refractory setting, demonstrating higher response rate (up to 50\%) than the conventional therapies [10-12]. They are being used as successful salvage therapies (monotherapy or combination) in patients with relapsed MM [13, 14].

With the changing therapeutic landscape for MM, wherein efforts are tailored to formulate the best possible treatment sequence, thalidomide, lenalidomide, and bortezomib are now being introduced as an inductive treatment strategy [15]. The use of thalidomide, lenalidomide, and bortezomib in newly diagnosed MM patients has been illustrated in a few studies, suggesting that early introduction of these drugs as front-line therapy may improve the therapeutic outcomes $[16,17]$. The results of the VISTA (NCT00111319) studies confirm the 
therapeutic advantage of bortezomib use in combination with melphalan-prednisone in patients with newly diagnosed $\mathrm{MM}$ who are ineligible for high-dose therapy [18, 19].

Bortezomib is the first proteasome inhibitor approved by the US Food and Drug Administration (FDA) for the treatment of patients with newly diagnosed as well as relapsed MM [20-22]. It is also approved in Europe and several other countries (including China) for the treatment of MM [23, 24]. Bortezomib exhibits a favorable safety profile and overall response rate of up to $67 \%$, when used in combination with dexamethasone in patients with relapsed and refractory MM [17, $25,26]$. Moreover, due to its unique mechanism of action, bortezomib is associated with low incidences of thromboembolic complications, and may provide a better safety profile than immunomodulatory agents (thalidomide and lenalidomide) [27].

Although the efficacy and safety of bortezomib is well established, validation of its benefits in patients of different ethnic backgrounds is warranted. This phase 4 observational study was designed to document the utilization, efficacy and safety of bortezomib in Chinese patients with relapse or refractory $\mathrm{MM}$, with at least one prior chemotherapy regimen, in a real-world practice scenario.

\section{METHODS}

\section{Study Population}

Male and female Chinese patients aged $\geq 18$ years, diagnosed with relapsed or refractory $\mathrm{MM}$ and having undergone at least one prior chemotherapy regimen were enrolled. All patients participating in the study had already initiated bortezomib therapy. Patients having contraindications listed in package insert $\left(\mathrm{VELCADE}^{\circledR}\right.$, registered trademark of Millennium Pharmaceuticals, Inc., Cambridge, USA) were disqualified. Patients with severe hepatic/renal impairment and platelet count below $25,000 / \mu \mathrm{L}$ were also excluded.

\section{Study Design and Treatment}

This phase 4 study was conducted in China (43 centers) between 17 March 2006 and 31 May 2010 (NCT01675245). The study consisted of a screening phase, treatment phase, and followup phase (3 years from the date of bortezomib initiation). Bortezomib was administered as an intravenous bolus twice weekly for 2 weeks (days 1, 4, 8 and 11) followed by a 10-day rest period (21-day total treatment cycle). A lapse period of atleast $72 \mathrm{~h}$ was to be maintained between 2 doses. Bortezomib (monotherapy/ combination), $1.3 \mathrm{mg} / \mathrm{m}^{2}$ (recommended dose) was administered for a maximum of 8 treatment cycles. The dose modification was allowed based on the treating physician's judgment (Table 1).

Prospective observational data were collected at baseline and at the end of each treatment cycle up to 8 cycles. Subsequently, the patients were followed up every 12 weeks for up to 3 years (from the date of initiation of bortezomib treatment) to collect the survival and future disease progression data. All concomitant medications, except use of bortezomib, were allowed.

\section{Assessments}

\section{Primary Analyses}

Retrospective data of prior usage of bortezomib were analyzed to determine treatment sequence (line of therapy), treatment cycles employed and average dose used $\left(\mathrm{mg} / \mathrm{m}^{2}\right)$. Efficacy 
Table 1 Utilization of bortezomib (safety analysis set)

\begin{tabular}{ll}
\hline Parameters & $\begin{array}{l}\text { No. of patients } \\
\boldsymbol{n}(\%)\end{array}$ \\
\hline Lines of initiating bortezomib treatment \\
3 & $248(48.2)$ \\
2 & $150(29.1)$ \\
$\geq 4$ & $108(21.0)$ \\
Others & $5(1.0)$ \\
Missing & $4(0.8)$ \\
Dose of bortezomib & Total $=524^{\mathrm{a}}$ \\
Mean, $\mathrm{mg} / \mathrm{m}^{2}$ (SD) & $1.18(0.45)$ \\
Mean $\mathrm{maximum} \mathrm{dose,} \mathrm{mg} / \mathrm{m}^{2}(\mathrm{SD})$ & $1.24(0.46)$ \\
Dose distribution, $n(\%)$ & \\
1.0 to $<1.3 \mathrm{mg} / \mathrm{m}^{2}$ & $355(67.7)$ \\
$\geq 1.3 \mathrm{mg} / \mathrm{m}^{2}$ & $88(16.8)$ \\
$<1.0 \mathrm{mg} / \mathrm{m}^{2}$ & $81(15.5)$ \\
Missing & 8 \\
\hline
\end{tabular}

Safety analysis set included patients who received at least 1 dose of bortezomib (with 1 or more prior treatments)

${ }^{\text {a }}$ Number of patients who received particular dose: distribution of bortezomib $\left(1.0\right.$ to $<1.3 \mathrm{mg} / \mathrm{m}^{2}+$ $\geq 1.3 \mathrm{mg} / \mathrm{m}^{2}+<1.0 \mathrm{mg} / \mathrm{m}^{2}$ )

assessments included: best response (complete response [CR], near CR [i.e., CR with positive immunofixation; nCR], partial response [PR], minimal response $[\mathrm{MR}]$, stable disease or progressive disease $[\mathrm{PD}]$ ); objective response rate (ORR $[\mathrm{CR}+\mathrm{nCR}+\mathrm{PR}+\mathrm{MR}])$; time to response (date of first dose of bortezomib until the date of the first response [CR/nCR/PR/MR]); duration of response (date of first response until $\mathrm{PD}$, relapse from CR [RCR], or death); time to progression (date of first dose of bortezomib until PD or RCR); and overall survival (OS [date of first dose of bortezomib until death]).

Safety assessments included: adverse events (AEs), clinical laboratory parameters, electrocardiograms, vital sign measurements, and physical examination.

\section{Exploratory Analyses}

The extent of healthcare resource utilization (emergency room visits, inpatient hospital stays [and reasons for hospitalization], and days of each hospital stay) associated with bortezomib therapy was determined.

\section{Statistical Methods}

As this was an observational study, no formal sample size calculation was performed. The data were analyzed using SAS, version 9.1.3 (Cary, NC, USA). The efficacy and safety data was summarized descriptively. Kaplan-Meier method (2-sided 95\% confidence intervals [CI]) was used for time-to-event data. The product limit estimator method was used to calculate the median OS, 25th, 50th (median) and 75th percentiles of time to progression, as well as the progression rate at different time points and the median duration of response in subgroups. Cox proportional hazards model (multiple factor analysis) was used for duration of response, time to progression, and OS. A multiple regression model was performed for time to response.

\section{Compliance with Ethics}

The Independent Ethics Committee or Institutional Review Board at each study site approved the protocol. All procedures followed were in accordance with the ethical standards of the responsible committee on human experimentation (institutional and national) and with the Helsinki Declaration of 1975, as revised in 2000 and 2008. Written informed consent was obtained from all patients for being included in the study. 
Table 2 Demographic and baseline characteristics (all enrolled analysis set)

\begin{tabular}{|c|c|}
\hline Parameters & $\begin{array}{l}\text { Bortezomib } \\
N=\mathbf{5 1 7}\end{array}$ \\
\hline Male, $n(\%)$ & $300(58.0)$ \\
\hline Age, years & $\begin{array}{l}488 ; 58.7 \\
(31.3-82.5)\end{array}$ \\
\hline Weight, $\mathrm{kg}, n$; mean (SD) & $512 ; 64.0(10.8)$ \\
\hline \multicolumn{2}{|l|}{ Myeloma type, $n(\%)$} \\
\hline Immunoglobulin $\mathrm{G}$ & $239(46.2)$ \\
\hline Immunoglobulin A & $124(24.0)$ \\
\hline Light chain & $98(19.0)$ \\
\hline Non-secretory & $20(3.9)$ \\
\hline Immunoglobulin $\mathrm{D}$ & $19(3.7)$ \\
\hline Immunoglobulin $\mathrm{M}$ & $5(1.0)$ \\
\hline Plasma cell leukemia & $4(0.8)$ \\
\hline Solitary plasmacytoma & $3(0.6)$ \\
\hline Smoldering & $1(0.2)$ \\
\hline Biclonal & $1(0.2)$ \\
\hline Missing & $3(0.6)$ \\
\hline $\begin{array}{l}\text { Time from initial diagnosis to first } \\
\text { dose, years, } n \text {; mean (SD) }\end{array}$ & $475 ; 2.0(3.1)$ \\
\hline \multicolumn{2}{|c|}{ Durie-Salmon staging at initial diagnosis, $n(\%)$} \\
\hline IIIa & $247(47.8)$ \\
\hline IIIb & $100(19.3)$ \\
\hline IIa & $76(14.7)$ \\
\hline Unclear & $50(9.7)$ \\
\hline I & $24(4.6)$ \\
\hline IIb & $18(3.5)$ \\
\hline Serum beta- 2 microglobulin, $\mathrm{mg} / \mathrm{L}$ & $\begin{array}{l}368 ; 3.9 \\
(0.9-39.9)\end{array}$ \\
\hline $\mathrm{C}$ reactive protein, $\mathrm{mg} / \mathrm{L}$ & $\begin{array}{l}252 ; 6.0 \\
(0-189.6)\end{array}$ \\
\hline Hemoglobin, g/L & $\begin{array}{l}500 ; 92.0 \\
\quad(11.0-175.0)\end{array}$ \\
\hline Platelet count, $10^{9} / \mathrm{L}$ & $\begin{array}{l}453 ; 163.0 \\
(50.0-461.0)\end{array}$ \\
\hline
\end{tabular}

Table 2 continued

\begin{tabular}{lc}
\hline Parameters & Bortezomib \\
& $\boldsymbol{N}=\mathbf{5 1 7}$ \\
\hline Serum creatinine, mg/dL & $191 ; 1.4$ \\
& $(1.0-7.6)$ \\
WBC, $10^{9} / \mathrm{L}$ & $493 ; 4.3$ \\
& $(1.2-28.4)$ \\
\hline
\end{tabular}

Data presented as $n$; median (range), unless otherwise specified. All enrolled analysis set included patients who were enrolled in the study

$S D$ standard deviation, $W B C$ white blood cells

\section{RESULTS}

\section{Patient Demographics and Baseline Characteristics}

Of the 517 patients enrolled in this study, 515 received the study drug. The enrolled patients had a median age of 58.7 years (range 31.3-82.5 years) and there was a marginally higher proportion of men than women. A total of $239 \quad(46.2 \%)$ patients had immunoglobulin G (IgG) and 247 (47.8\%) patients had stage IIIa MM (as per DurieSalmon [DS] criteria) (Table 2). A total of 231 $(44.7 \%)$ patients were treated with 2 prior lines of chemotherapy and 135 (26.1\%) patients received $\geq 3$ lines of chemotherapy. Overall, 475 (32.3\%) patients received a combination of vincristine, adriamycin, and dexamethasone (VAD) as prior therapy. A small minority of patients had been previously treated with bortezomib (2.5\%). The greatest proportion of patients $(24.4 \%$, $n=126$ ) obtained PR as best response to previous chemotherapy.

A total of 503 patients out of 515 discontinued during the treatment phase (including discontinuations due to physician's decision). Treatment discontinuations were primarily due to financial reasons (14.5\%, 
$n=73)$ followed by disease remission (13.7\%, $n=69) \quad$ and $\quad$ AEs $\quad(10.7 \%, \quad n=54)$. Discontinuations were unclear for 48 (9.5\%) patients; whereas, other discontinuations were due to death (4\%), loss to follow-up/noncompliance/voluntary withdrawal (4\%), transplant (3.2\%), no response/progression (3.2\%), use of other chemotherapy (1.2\%), others (1.0\%) and hospital beds (0.2\%). Overall, the reasons for discontinuations of 176 (35.0\%) patients who maintained bortezomib after 8 cycles were unknown.

\section{Utilization of Bortezomib}

A total of 248 (48.2\%) enrolled patients used bortezomib as third-line treatment (Table 2). The majority $(75.6 \%[n=214 / 283])$ of patients had PD at the start of the study who received initial bortezomib treatment.

\section{Extent of Exposure}

A mean of 3.3 cycles of bortezomib treatment was administered. More than half of patients ( $n=345,67.0 \%)$ used bortezomib at a dose of 1.0 to $<1.3 \mathrm{mg} / \mathrm{m}^{2} ; 18.1 \%$ received $\geq 1.3 \mathrm{mg} / \mathrm{m}^{2}$ dose (very few patients received $1.6 \mathrm{mg} / \mathrm{m}^{2}$, biweekly). The mean dose administered was $1.2 \mathrm{mg}$. Most patients received bortezomib as combination therapy (461/515 patients); the majority $(n=282)$ received bortezomib with dexamethasone. Other combination therapies administered during the study were bortezomib, adriamycin, and dexamethasone (VAD; $n=36$ ); bortezomib, cyclophosphamide, and dexamethasone (VCD; $n=10)$; bortezomib, melphalan, and prednisone (VMP; $n=17$ ); bortezomib and thalidomide (VT; $n=3$ ); bortezomib, thalidomide, adriamycin and dexamethasone (VTAD; $n=8$ ); bortezomib, thalidomide, and dexamethasone (VTD; $n=44)$; and bortezomib, thalidomide, melphalan, and prednisone (VTMP; $n=7$ ).

\section{Efficacy}

\section{Best Response to Bortezomib Treatment}

Overall, majority of patients had PR as best response $(42.3 \%, n=202)$. About $118(24.7 \%)$ patients demonstrated CR, $56 \quad(11.7 \%)$ demonstrated nCR, 49 (10.3\%) demonstrated MR and 35 (7.3\%) had stable disease. Few patients demonstrated PD $(3.8 \%, n=18)$ (Table 3). The ORR (CR $+\mathrm{nCR}+\mathrm{PR}+\mathrm{MR})$ in 478 evaluable patients was $88.9 \%$.

The subgroup analysis of the response data by lines of treatment, disease stage (as per DS staging), average dose of bortezomib, and treatment cycle showed similar trend of best response across subgroups (Table 3); the highest number of patients had PR, with few demonstrating stable disease or PD. A higher proportion of patients receiving bortezomib at dose $\geq 1.3 \mathrm{mg} / \mathrm{m}^{2}$ achieved CR (29.2\%), compared to those receiving 1.0 to $<1.3 \mathrm{mg} / \mathrm{m}^{2}$ and $<1.0 \mathrm{mg} / \mathrm{m}^{2}$ doses ( $24.7 \%$ and $16.4 \%$, respectively).

\section{Time to Response, Duration of Response, Time to Progression and Overall Survival}

The mean (standard deviation [SD]) time to response for bortezomib treatment was 36.1 (34.8) days (median 27 days; range 21-40 days). The majority of patients maintained best response to bortezomib treatment up to day 30 (88.3\%); however, as time progressed there was gradual decrease in the percentage of patients maintaining response with only $7.2 \%$ demonstrating response by 480 days. The median time to progression was 415 days. The disease progression rate was minimal by day 30 (2.1\%), and increased gradually to $100 \%$ by day 720. Median overall survival time was 475 days. These results corroborated with the OS rate that 
Table 3 Best response with bortezomib treatment in patients with relapsed/refractory multiple myeloma (efficacy analysis set)

\begin{tabular}{llllllll}
\hline Overall best response, & CR & nCR & PR & MR & Stable disease & PD & Total \\
$n(\%$ of total $)$ & $118(24.7)$ & $56(11.7)$ & $202(42.3)$ & $49(10.3)$ & $35(7.3)$ & $18(3.8)$ & $478(100)$
\end{tabular}

Best response in different subgroups, $n$ (\% of total)

Lines of treatment

$\begin{array}{lclllllr}2 & 35(25.9) & 16(11.9) & 50(37.0) & 18(13.3) & 9(6.7) & 7(5.2) & 135(100) \\ 3 & 54(23.0) & 38(16.2) & 97(41.3) & 23(9.8) & 17(7.2) & 6(2.6) & 235(100) \\ \geq 4 & 28(28.0) & 2(2.0) & 53(53.0) & 8(8.0) & 6(6.0) & 3(3.0) & 100(100) \\ \text { Others }^{\mathrm{a}} & 1(25.0) & 0 & 1(25.0) & 0 & 2(50.0) & 0 & 4(100) \\ \text { Durie-Salmon staging } & & & & & & & \\ \text { I } & 7(29.2) & 2(8.3) & 9(37.5) & 2(8.3) & 2(8.3) & 2(8.3) & 24(100) \\ \text { IIA } & 26(36.1) & 8(11.1) & 22(30.6) & 11(15.3) & 5(6.9) & 0(0.0) & 72(100) \\ \text { IIB } & 3(17.6) & 2(11.8) & 10(58.8) & 0(0.0) & 1(5.9) & 1(5.9) & 17(100) \\ \text { IIIA } & 56(24.9) & 26(11.6) & 103(45.8) & 21(9.3) & 10(4.4) & 9(4.0) & 225(100) \\ \text { IIIB } & 18(18.9) & 14(14.7) & 38(40.0) & 12(12.6) & 9(9.5) & 4(4.2) & 95(100)\end{array}$

Average dose of bortezomib

$\begin{array}{llllllll}<1.0 \mathrm{mg} / \mathrm{m}^{2} & 10(16.4) & 7(11.5) & 26(42.6) & 9(14.8) & 5(8.2) & 4(6.6) & 61(100) \\ 1.0 \text { to }<1.3 \mathrm{mg} / \mathrm{m}^{2} & 72(24.7) & 36(12.4) & 127(43.6) & 27(9.3) & 19(6.5) & 10(3.4) & 291(100) \\ \geq 1.3 \mathrm{mg} / \mathrm{m}^{2} & 35(29.2) & 12(10.0) & 47(39.2) & 12(10.0) & 10(8.3) & 4(3.3) & 120(100)\end{array}$

Best response by cycle

\begin{tabular}{llllllll}
1 & $43(9.9)$ & $31(7.1)$ & $217(50.0)$ & $66(15.2)$ & $53(12.2)$ & $24(5.5)$ & $434(100)$ \\
2 & $56(16.2)$ & $43(12.5)$ & $155(44.9)$ & $33(9.6)$ & $27(7.8)$ & $31(9.0)$ & $345(100)$ \\
3 & $47(21.3)$ & $30(13.6)$ & $92(41.6)$ & $22(10.0)$ & $18(8.1)$ & $12(5.4)$ & $221(100)$ \\
4 & $54(31.4)$ & $18(10.5)$ & $71(41.3)$ & $12(7.0)$ & $8(4.7)$ & $9(5.2)$ & $172(100)$ \\
5 & $32(30.2)$ & $11(10.4)$ & $43(40.6)$ & $5(4.7)$ & $7(6.6)$ & $8(7.6)$ & $106(100)$ \\
6 & $24(35.3)$ & $2(2.9)$ & $30(44.1)$ & $3(4.4)$ & $4(5.9)$ & $5(7.4)$ & $68(100)$ \\
7 & $14(33.3)$ & $3(7.1)$ & $15(35.7)$ & $3(7.1)$ & $3(7.1)$ & $4(9.5)$ & $42(100)$ \\
8 & $14(45.2)$ & $0(0)$ & $12(38.7)$ & $1(3.2)$ & $2(6.5)$ & $2(6.5)$ & $31(100)$ \\
\hline
\end{tabular}

Efficacy analysis set: included patients who received at least 1 dose of bortezomib (with 1 or more prior treatments) $C R$ complete response, $M R$ minimal response, $n C R$ near complete response (complete response with positive immunofixation), $P D$ progressive disease, $P R$ partial response

${ }^{a}$ Consolidation therapy (treatment after autologous stem cell transplant) or missing

improved gradually from $97.2 \%$ (by day 30 ) to $25.2 \%$ (by day 720) (Table 4). Based on subgroup analysis, patients receiving an average dosage $\geq 1.3 \mathrm{mg} / \mathrm{m}^{2}$ tended to have longer duration of response and higher OS rate while those receiving average dosage $<1.0 \mathrm{mg}$ / 
Table 4 Overall duration of response, time to progression and overall survival with bortezomib treatment in patients with relapsed/refractory multiple myeloma (efficacy analysis set)

\begin{tabular}{lll}
\hline Time (days) & $\begin{array}{l}\text { Patients maintaining } \\
\text { response, \% (SE) }\end{array}$ & 95\% CI \\
\hline
\end{tabular}

Duration of response

$\begin{array}{ll}30 & 88.3(1.7) \\ 60 & 83.4(2.2) \\ 120 & 81.6(2.4) \\ 240 & 72.5(3.6) \\ 360 & 59.9(6.1) \\ 480 & 55.3(7.2) \\ 600 & 55.3(7.2) \\ 720 & 0.0(0.0)\end{array}$

$84.5,91.2$

$78.6,87.3$

$76.3,85.8$

$64.8,78.8$

$46.8,70.7$

$40.2,68.0$

$40.2,68.0$

Time to progression

$\begin{array}{lll}30 & 2.1(0.7) & 1.1,4.1 \\ 60 & 6.9(1.3) & 4.7,10.1 \\ 120 & 16.1(2.3) & 12.2,21.2 \\ 240 & 24.1(3.2) & 18.5,31.1 \\ 360 & 35.9(5.4) & 26.4,47.4 \\ 480 & 59.3(9.6) & 41.6,77.7 \\ 600 & 59.3(9.6) & 41.6,77.7 \\ 720 & 100.0(0.0) & -\end{array}$

Overall survival

\begin{tabular}{lll}
30 & $97.2(0.8)$ & $95.1,98.3$ \\
60 & $94.1(1.2)$ & $91.3,96.0$ \\
120 & $89.1(1.8)$ & $85.0,92.1$ \\
240 & $79.0(2.9)$ & $72.5,84.1$ \\
360 & $66.6(4.5)$ & $57.1,74.5$ \\
480 & $49.9(6.6)$ & $36.5,62.0$ \\
600 & $35.3(7.7)$ & $20.7,50.2$ \\
720 & $25.2(8.2)$ & $11.2,42.0$ \\
\hline
\end{tabular}

Quantile and 95\% CI of time to progression

\begin{tabular}{ll}
\hline Quantile (\%) & 95\% CI \\
\hline 75 & $705.0(429.00,705.00)$ \\
50 & $415.0(382.00,705.00)$ \\
25 & $268.0(186.00,354.00)$
\end{tabular}

Efficacy analysis set: included patients who received at least 1 dose of bortezomib (with 1 or more prior treatments) $C I$ confidence interval, $S E$ standard error
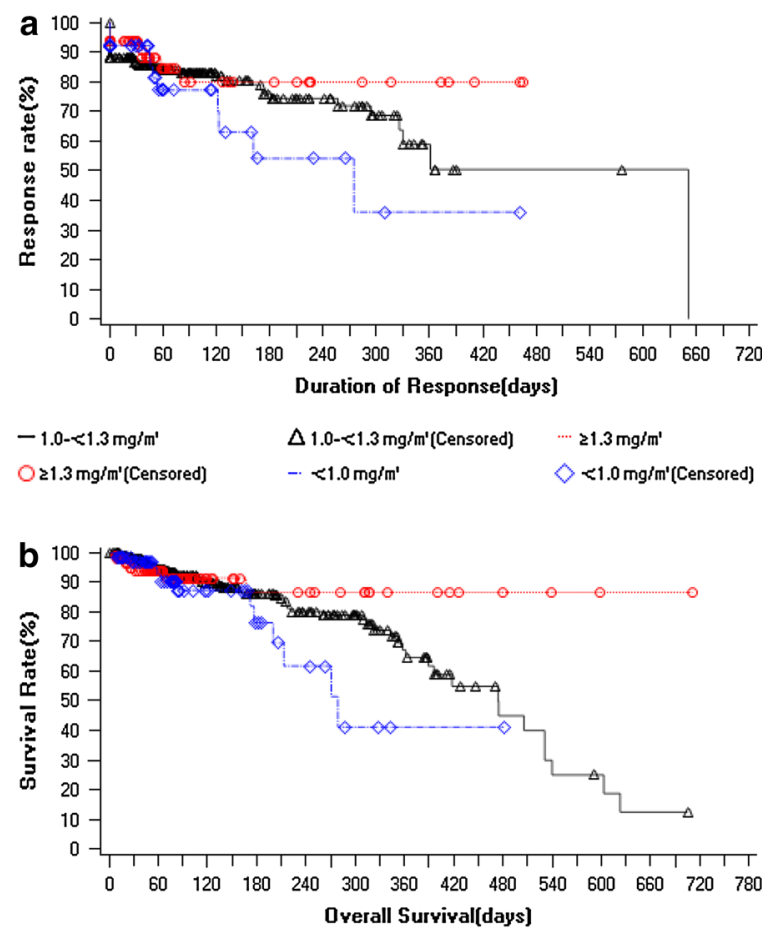

$$
-1.0-<1.3 \mathrm{mg} / \mathrm{m}^{\prime}
$$$$
021.3 \mathrm{mg} / \mathrm{m}^{\prime} \text { (Censored) }
$$

$$
\begin{array}{ll}
\Delta 1.0-<1.3 \mathrm{mg} / \mathrm{m}^{\prime} \text { (Censored) } & \cdots . .21 .3 \mathrm{mg} / \mathrm{m}^{\prime} \\
-.<1.0 \mathrm{mg} / \mathrm{m}^{\prime} & \diamond<1.0 \mathrm{mg} / \mathrm{m}^{\prime} \text { (Censored) }
\end{array}
$$

Fig. 1 Kaplan-Meier curve of a duration of response and b overall survival in different subgroups of bortezomib dosage in patients with relapsed/refractory multiple myeloma (efficacy analysis set). Efficacy analysis set: included patients who received at least 1 dose of bortezomib (with 1 or more prior treatments)

$\mathrm{m}^{2}$ had shorter duration of response and low OS rate, compared with the other 2 subgroups (Fig. 1).

The duration of response in patients receiving dosage $\geq 1.0$ and $<1.0 \mathrm{mg} / \mathrm{m}^{2}$ is as follows (median $[95 \% \mathrm{CI}]) \geq 1.0 \mathrm{mg} / \mathrm{m}^{2}$ (651 days [361, $651]) ;<1.0 \mathrm{mg} / \mathrm{m}^{2}(275[123,-]) ; p=0.23$. The time to progression was shorter in patients who received $<1.0 \mathrm{mg} / \mathrm{m}^{2}$ dose compared to patients who received $\geq 1.0 \mathrm{mg} / \mathrm{m}^{2}$ dose (median $[95 \%$ $\mathrm{CI}]) \geq 1.0 \mathrm{mg} / \mathrm{m}^{2}(415[386,705]) ;<1.0 \mathrm{mg} / \mathrm{m}^{2}$ (329 $[186,-]) ; p=0.22$ ). The OS (median $[95 \%$ $\mathrm{CI}]) \geq 1.0 \mathrm{mg} / \mathrm{m}^{2}(531[418,623]) ;<1.0 \mathrm{mg} / \mathrm{m}^{2}$ $(279[200,-]) ; p=0.059)$ was shorter for patients who received $<1.0 \mathrm{mg} / \mathrm{m}^{2}$ dose compared with patients who received $\geq 1.0 \mathrm{mg} / \mathrm{m}^{2}$ dose. 


\section{Safety}

Overall, 63.9\% patients experienced at least 1 AE. The most frequently reported $\mathrm{AE}$ was thrombocytopenia $(14.4 \%, n=74)$ (Table 5). Most of the AEs $(\sim 35 \%)$ were grade 1 or 2 in severity, with few grade $3(16.7 \%)$ or grade 4 (6.4\%). Drug-related AEs occurred in $53.8 \%$ of patients. The incidence of serious adverse events (SAE) was low (6.4\%); deaths and lung infections were reported in nine patients each. Thrombocytopenia as a SAE was reported by two patients.

The most commonly ( $\geq 10 \%$ of patients) reported AEs of special interest (assessed as per WHO Common Toxicity Criteria) were infection (16.3\%, $n=84)$, thrombocytopenia $(14.8 \%, n=76)$, diarrhea $(14.0 \%, n=72)$, peripheral sensory neuropathy $(10.7 \%$, $n=55)$, weakness $(11.8 \%, \quad n=61), \quad$ and paresthesia $(10.7 \%, n=55)$. The majority (55.2\%, $n=284$ ) of these AEs were $\leq$ grade 2 in severity, with few grade $3(15.0 \%, n=77)$ or 4 $(4.1 \%, n=21)$ AEs.

\section{Healthcare Utilization}

In total, 148 (28.0\%) of the enrolled patients did not require any hospital stay. Of the patients who were hospitalized, most $(22.8 \%, n=118)$ required only one stay (mean days [SD], 31.9 [55.6]). Of the 1,039 types of hospitalization, the most frequent was voluntary hospitalization $(92.8 \%, n=964)$, followed by emergency $(6.1 \%$, $n=63)$, acute $(0.7 \%, n=7)$, and unknown (including case report form unfilled) $(0.5 \%$, $n=5)$.

\section{DISCUSSION}

The therapeutic paradigm for $\mathrm{MM}$ has now shifted in light of the demonstrated therapeutic advantages of proteasome inhibitors and immunomodulators over conventional strategies [28, 29]. As a result, these drugs have emerged as a more feasible treatment option for patients with relapsed/refractory MM, particularly those ineligible for high-dose chemotherapy. Bortezomib is the first proteasome inhibitor approved for treatment

Table 5 Adverse events in $\geq 5 \%$ of bortezomib-treated patients with relapsed/refractory multiple myeloma (safety analysis set)

\begin{tabular}{lcllll}
\hline & $\begin{array}{l}\text { Grade 1 } \\
\boldsymbol{n}(\%)\end{array}$ & $\begin{array}{l}\text { Grade 2 } \\
\boldsymbol{n}(\%)\end{array}$ & $\begin{array}{l}\text { Grade 3 } \\
\boldsymbol{n}(\%)\end{array}$ & $\begin{array}{l}\text { Grade 4 } \\
\boldsymbol{n}(\%)\end{array}$ & $\begin{array}{l}\text { Total } \\
\boldsymbol{n}(\%)\end{array}$ \\
\hline Total patients with AEs $^{\text {\% }}$ & $200(38.8)$ & $171(33.2)$ & $86(16.7)$ & $33(6.4)$ & $329(63.9)$ \\
Thrombocytopenia $^{\mathrm{a}}$ & $18(3.5)$ & $31(6.0)$ & $31(6.0)$ & $6(1.2)$ & $74(14.4)$ \\
Diarrhea & $37(7.2)$ & $27(5.2)$ & $7(1.4)$ & 0 & $71(13.8)$ \\
Peripheral neuropathy & $34(6.6)$ & $20(3.9)$ & $3(0.6)$ & 0 & $55(10.7)$ \\
Hypoesthesia & $33(6.4)$ & $18(3.5)$ & $5(1.0)$ & 0 & $52(10.1)$ \\
Asthenia & $41(8.0)$ & $13(2.5)$ & $2(0.4)$ & 0 & $51(9.9)$ \\
Lung infection & $7(1.4)$ & $22(4.3)$ & $10(1.9)$ & $8(1.6)$ & $40(7.8)$ \\
Herpes zoster & $14(2.7)$ & $12(2.3)$ & $3(0.6)$ & 0 & $30(5.8)$ \\
\hline
\end{tabular}

Safety analysis set: included patients who received at least 1 dose of bortezomib (with 1 or more prior treatments) $A E$ adverse event

${ }^{a}$ Platelet count $<50 \times 10^{9} / \mathrm{L}$ 
of patients with relapsed as well as newly diagnosed MM [30]. The pivotal studies conducted so far establish the efficacy and safety of bortezomib in the Caucasian population [10, 11]. This observational study simulating the real-world practice scenario provides insight into the therapeutic feasibility of bortezomib in Chinese patients with relapsed or refractory $\mathrm{MM}$ following at least one prior chemotherapy regimen.

Notably in this study, bortezomib treatment resulted in ORR of $88.9 \%$, a rate comparatively superior to the ORR achieved in the Global studies assessing the therapeutic benefits of bortezomib plus dexamethasone in a predominantly Caucasian population. (CREST, 62\%, SUMMIT, $35 \%$ and APEX, $43 \%$ [NCT00048230]) [10-12]. The population enrolled in these global studies had baseline characteristics similar to the population of this study (age of $\sim 60$ years and majority had Durie-Salmon staging of stage IIIa). When compared with the VOBS trial conducted in the Chinese population, the ORR $(>70 \%)$ was similar to that noted in this study. Taken together, these studies highlight the difference in treatment sensitivity within populations belonging to diverse ethnic backgrounds (Caucasian and Asian) [31]. Of note, the treatment strategies employed for these two populations were not similar, which might have also contributed to the higher ORR observed in Chinese patients (VOBS trial) compared with Caucasian patients (Global trials). In the Caucasian population, bortezomib was initiated as monotherapy, and dexamethasone was introduced during the course of treatment only if required; while in the Chinese population, bortezomib was initiated as combination therapy in most patients. Of the evaluable patients in this study, the majority demonstrated PR. Although stable disease status was not achieved in most of the patients, those demonstrating disease progression were notably few. These findings were consistent with the APEX study [12] which supports the therapeutic advantage of bortezomib when introduced early as salvage treatment in the course of disease.

The median time to first response was notably shorter in this study (27 days) compared with results from studies in Caucasians (1.3-1.5 months) [10, 11], but was consistent with an earlier study in Chinese population reporting median time to response of 33-38 days [31]. Further, the duration of response was longer in this population ( 20 months) compared with Caucasians (12.7 months). A longer duration of response generally translates into improved treatment outcomes [12]. The disease progression rate in this study was minimal by day 30 and increased gradually as time progressed. Overall, this observational study in real-world setting demonstrates the utilization and feasibility of bortezomib, confirming its use in Chinese patients with relapse or refractory MM.

Further, no unexpected safety findings were observed in this Chinese population. The most common AEs $(\geq 10 \%)$ were decrease in platelet count, diarrhea, peripheral neuropathy, and hypoesthesia. Overall, bortezomib treatment was associated with manageable AEs and did not limit the continuity of therapy. The incidence of deaths, SAEs and AEs leading to discontinuation were overall low. The safety outcomes indicated that treatment with bortezomib produces a manageable toxicity profile in the Chinese population.

\section{Limitations}

One limitation of this study was the short follow-up period. A longer than 3-year followup period would help to better interpret the 
survival data. This corroborated with the VISTA study wherein the follow-up period was similar to our study, and no conclusive results were obtained with respect to OS. This study lacked any novel findings or any additional treatment benefits related to bortezomib. The treatment effects noted in the Chinese population were similar to the known therapeutic outcomes of bortezomib.

\section{CONCLUSION}

This study demonstrates that a bortezomibbased regimen was feasible in Chinese patients with relapse or refractory MM. Bortezomib was associated with good response rates, and a manageable safety profile consistent with previous studies and clinical experience. Notably, patients receiving the standard dosage $\left(1.3 \mathrm{mg} / \mathrm{m}^{2}\right)$ and longer treatment duration demonstrated better survival benefits with bortezomib therapy.

\section{ACKNOWLEDGMENTS}

Sponsorship and article processing charges for this study were funded by Xian-Janssen Pharmaceuticals, Beijing, China. The sponsor also funded the manuscript development. The authors would like to thank Dr. Ananya Chikramane (SIRO Clinpharm Pvt. Ltd.) for writing assistance, and Dr. Namit Ghildyal (Janssen Research and Development, LLC) for additional editorial assistance. All authors meet the ICMJE criteria for authorship for this manuscript, had full access to all of the data in this study and take complete responsibility for the integrity of the data, of the work as a whole and of the accuracy of the data analysis. All authors have given final approval for the version to be published. The authors thank the study participants, without whom this study would not have been accomplished, as well as the following investigators for their participation in this study: Liu Kaiyan, $\mathrm{Yu} \mathrm{Li}$, Qiu Lugui, Shao Zonghong, Wang Chun, Li Juan, Du Xin, Hou Ming, Zhao Hongguo, Ouyang Jian, Wu Peide, Yu Kang, Liu Ting, Zou Ping, Chen Xiequn, Ma Jun, Hu Jianda, Zhou Jianfeng, Zhang Quanying, Chen Baoan, Shao Zonghong, Li Wei, Lu Zhenxia, Liu Nan, Yang Linhua, Ke Xiaoyan, Li Lanping, Ge Linfu, He Xupeng, Li Xiaolin, Ma Jianxia, Ouyang Mufang, Zhang Quanying, Li Xiao, Wang Zhao, Ma Yigai.

Compliance with ethics guidelines. The Independent Ethics Committee or Institutional Review Board at each study site approved the protocol. All procedures followed were in accordance with the ethical standards of the responsible committee on human experimentation (institutional and national) and with the Helsinki Declaration of 1975, as revised in 2000 and 2008. Written informed consent was obtained from all patients for being included in the study.

Conflict of interest. Z. Shen, Y. Li, Z. Liu, M. Lin and $\mathrm{W}$. Chen have no conflict of interest. $X$. Huang received funding from Clinical Subjects Key Project of the Ministry of Health, National Natural Science Foundation of China, and The Key Program of National Natural Science Foundation of China. Y. Zhou received research fund from State Administration of Traditional Chinese Medicine, and Molecular Biology Application Research Funds of Chinese Medicine Association. J. Hou received consultancy from Novartis, received honoraria from Novartis and Xian-Janssen Pharmaceutical, and received research funding from Xian-Janssen Pharmaceutical. T Zhao is an 
employee of Xian-Janssen Pharmaceutical. L. Wang is an employee of Xian-Janssen Pharmaceutical. K. $\mathrm{Wu}$ is an employee of Xian-Janssen Pharmaceutical.

Open Access. This article is distributed under the terms of the Creative Commons Attribution Noncommercial License which permits any noncommercial use, distribution, and reproduction in any medium, provided the original author(s) and the source are credited.

\section{REFERENCES}

1. Gupta M, Pal R, Tikoo D. Multiple myeloma: the disease and its treatment. Int $\mathrm{J}$ Basic Clin Pharmacol. 2013;2(2):103-21.

2. Becker N. Epidemiology of multiple myeloma. Recent Results Cancer Res. 2011;183:25-35.

3. Huang SY, Yao M, Tang JL, Lee WC, Tsay W, Cheng $\mathrm{AL}$, et al. Epidemiology of multiple myeloma in Taiwan: increasing incidence for the past 25 years and higher prevalence of extramedullary myeloma in patients younger than 55 years. Cancer. 2007;110(4):896-905.

4. Rajkumar SV. Multiple myeloma: 2013 update on diagnosis, risk-stratification, and management. Am J Hematol. 2013;88(3):226-35.

5. Zeng Z, Lin J, Chen J. Bortezomib for patients with previously untreated multiple myeloma: a systematic review and meta-analysis of randomized controlled trials. Ann Hematol. 2013;92(7):935-43.

6. Jakubowiak A. Management strategies for relapsed/ refractory multiple myeloma: current clinical perspectives. Semin Hematol. 2012;49(Suppl 1):S16-32.

7. Fonseca R, Stewart AK. Targeted therapeutics for multiple myeloma: the arrival of a risk-stratified approach. Mol Cancer Ther. 2007;6(3):802-10.

8. Blade J, Rosinol L. Changing paradigms in the treatment of multiple myeloma. Haematologica. 2009;94(2):163-6.

9. Larocca A, Palumbo A. Evolving paradigms in the treatment of newly diagnosed multiple myeloma. J Natl Compr Canc Netw. 2011;9(10):1186-96.
10. Jagannath S, Barlogie B, Berenson J, et al. A phase 2 study of two doses of bortezomib in relapsed or refractory myeloma. Br J Haematol. 2004;127:165-72.

11. Richardson PG, Barlogie B, Berenson J, et al. A phase 2 study of bortezomib in relapsed, refractory myeloma. N Engl J Med. 2003;348:2609-17.

12. Richardson PG, Sonneveld P, Schuster M, et al. Extended follow-up of a phase 3 trial in relapsed multiple myeloma: final time-to-event results of the APEX trial. Blood. 2007;110:3557-60.

13. van de Donk NW, Lokhorst HM, Dimopoulos M, Cavo M, Morgan G, Einsele H, et al. Treatment of relapsed and refractory multiple myeloma in the era of novel agents. Cancer Treat Rev. 2011;37(4):266-83.

14. Richardson P, Mitsiades C, Schlossman R, Ghobrial I, Hideshima T, Chauhan D, et al. The treatment of relapsed and refractory multiple myeloma. Hematology Am Soc Hematol Educ Program. 2007;2007(1):317-23.

15. Mohty B, El-Cheikh J, Yakoub-Agha I, Avet-Loiseau $\mathrm{H}$, Moreau P, Mohty M. Treatment strategies in relapsed and refractory multiple myeloma: a focus on drug sequencing and 'retreatment' approaches in the era of novel agents. Leukemia. 2012;26(1):73-85.

16. Harousseau JL, Attal M, Leleu X, Troncy J, Pegourie B, Stoppa AM, et al. Bortezomib plus dexamethasone as induction treatment prior to autologous stem cell transplantation in patients with newly diagnosed multiple myeloma: results of an IFM phase II study. Haematologica. 2006;91(11):1498-505.

17. Jagannath S, Durie BG, Wolf J, Camacho E, Irwin D, Lutzky J, et al. Bortezomib therapy alone and in combination with dexamethasone for previously untreated symptomatic multiple myeloma. $\mathrm{Br} \mathrm{J}$ Haematol. 2005;129(6):776-83.

18. San Miguel JF, Schlag R, Khuageva NK, Dimopoulos MA, Shpilberg O, Kropff M, et al. Bortezomib plus melphalan and prednisone for initial treatment of multiple myeloma. N Engl J Med. 2008;359(9):906-17.

19. Mateos MV, Richardson PG, Schlag R, Khuageva NK, Dimopoulos MA, Shpilberg O, et al. Bortezomib plus melphalan and prednisone compared with melphalan and prednisone in previously untreated multiple myeloma: updated follow-up and impact of subsequent therapy in the phase III VISTA trial. J Clin Oncol. 2010;28(13):2259-66.

20. Velcade ${ }^{\circledR}$, (bortezomib), Prescribing Information. 2003. www.accessdata.fda.gov/drugsatfda_docs/ label/.../021602s015lbl.pdf. Accessed July 14, 2014. 
21. Kane RC, Bross PF, Farrell AT, Pazdur R. Velcade: US FDA approval for the treatment of multiple myeloma progressing on prior therapy. Oncologist. 2003;8(6):508-13.

22. Kane RC, Dagher R, Farrell A, Ko CW, Sridhara R, Justice R, et al. Bortezomib for the treatment of mantle cell lymphoma. Clin Cancer Res. 2007;13(18):5291-4.

23. www.myeloma-euronet.org. Myeloma Euronet: Treatment with Bortezomib. 2013. http://www.myelomaeuronet.org/en/multiple-myeloma/treatment-withbortezomibphp. Accessed July 14, 2014.

24. LoRusso PM, Venkatakrishnan K, Ramanathan RK, Sarantopoulos J, Mulkerin D, Shibata SI, et al. Pharmacokinetics and safety of bortezomib in patients with advanced malignancies and varying degrees of liver dysfunction: phase I NCI Organ Dysfunction Working Group Study NCI-6432. Clin Cancer Res. 2012;18(10):2954-63.

25. Mikhael JR, Belch AR, Prince HM, Lucio MN, Maiolino A, Corso A, et al. High response rate to bortezomib with or without dexamethasone in patients with relapsed or refractory multiple myeloma: results of a global phase $3 \mathrm{~b}$ expanded access program. Br J Haematol. 2009;144(2):169-75.

26. Richardson PG, Barlogie B, Berenson J, Singhal S, Jagannath S, Irwin DH, et al. Extended follow-up of a phase II trial in relapsed, refractory multiple myeloma: final time-to-event results from the SUMMIT trial. Cancer. 2006;106(6):1316-9.

27. Lonial S, Richardson PG, San Miguel J, Sonneveld P, Schuster MW, Blade J, et al. Characterisation of haematological profiles and low risk of thromboembolic events with bortezomib in patients with relapsed multiple myeloma. $\mathrm{Br} \mathrm{J}$ Haematol. 2008;143(2):222-9.

28. Katzel JA, Hari P, Vesole DH. Multiple myeloma: charging toward a bright future. CA Cancer J Clin. 2007;57:301-18.

29. Bae J, Munshi NC, Anderson KC. Immunotherapy strategies in multiple myeloma. Hematol Oncol Clin North Am. 2014;28:927-43.

30. Mujtaba T, Dou QP. Advances in the understanding of mechanisms and therapeutic use of bortezomib. Discov Med. 2011;12:471-80.

31. Yuan ZG, Jin J, Huang XJ, Li Y, Chen WM, Liu ZG, et al. Different dose combinations of bortezomib and dexamethasone in the treatment of relapsed or refractory myeloma: an open-label, observational, multi-center study in China. Chin Med J (Engl). 2011;124(19):2969-74. 